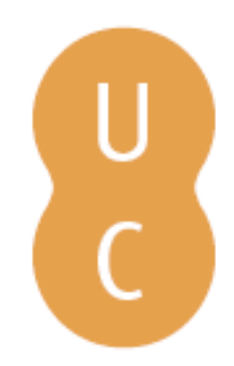

\title{
nombalina
}

\section{Espaços para o dever e o lazer num modelo de educação humanística (1599)}

Autor(es): $\quad$ Miranda, Margarida

Publicado por: Associação Portuguesa de Estudos Clássicos; Imprensa da

Universidade de Coimbra

URL

persistente: URI:http://hdl.handle.net/10316.2/31814

DOI: $\quad$ DOI:http://dx.doi.org/10.14195/978-972-98142-2-8_8

Accessed : $\quad$ 26-Apr-2023 12:11:50

A navegação consulta e descarregamento dos títulos inseridos nas Bibliotecas Digitais UC Digitalis, UC Pombalina e UC Impactum, pressupõem a aceitação plena e sem reservas dos Termos e Condições de Uso destas Bibliotecas Digitais, disponíveis em https://digitalis.uc.pt/pt-pt/termos.

Conforme exposto nos referidos Termos e Condições de Uso, o descarregamento de títulos de acesso restrito requer uma licença válida de autorização devendo o utilizador aceder ao(s) documento(s) a partir de um endereço de IP da instituição detentora da supramencionada licença.

Ao utilizador é apenas permitido o descarregamento para uso pessoal, pelo que o emprego do(s) título(s) descarregado(s) para outro fim, designadamente comercial, carece de autorização do respetivo autor ou editor da obra.

Na medida em que todas as obras da UC Digitalis se encontram protegidas pelo Código do Direito de Autor e Direitos Conexos e demais legislação aplicável, toda a cópia, parcial ou total, deste documento, nos casos em que é legalmente admitida, deverá conter ou fazer-se acompanhar por este aviso.

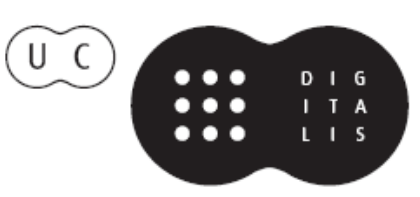




\section{Espaços e Paisagens}

\section{Antiguidade Clássica e Heranças Contemporâneas}

Vol. Il Línguas e Literaturas. Idade Média. Renascimento. Recepção

Francisco de Oliveira, Cláudia Teixeira, Paula Barata Dias (Coords.)

IMPRENSA DA UNIVERSIDADE DE COIMBRA 


\title{
ESPAÇOS PARA O DEVER E O LAZER NUM MODELO DE EDUCAÇÃO HUMANÍSTICA (1599)
}

\author{
Margarida Miranda \\ Universidade de Coimbra
}

\begin{abstract}
Drawing upon the Ratio Studiorum of the Society of Jesus, recently published in a brand new Portuguese version, the original version (1599) of which embodies the guidelines for the studies at the Jesuit high schools, in Europe and throughout the world, this essay highlights some features of the academic regulations, and it focuses in particular on the most innovative ones as well as on those that most clearly draw inspiration from Greek-roman social models.
\end{abstract}

Keywords: colleges, education, history of Jesuits, Humanism, ratio studiorum.

Palavras-chave: colégios, educação, História dos Jesuítas, Humanismo, Ratio Studiorum.

A Ratio Studiorum dos colégios da Companhia de Jesus foi elaborada ao longo de várias décadas, até tomar forma definitiva em 1599, com a promulgação de um amplo conjunto de regras que se enviou a todas as províncias, após sucessivos aperfeiçoamentos resultantes das primeiras aplicações no terreno. ${ }^{1}$

Tendo em conta a importância destes colégios na educação da Europa - quando praticamente não havia outras respostas à procura crescente de escolarização por parte das populações, quando a procura escolar se generalizara e sofrera uma forte aceleração, (ou não estivéssemos nós no século da revolução da imprensa) - tendo em conta também o carácter fundador deste documento sobre outras instituições escolares que nasceram à sua imagem, o que procurarei fazer no escasso tempo da minha intervenção será descrever alguns aspectos da organização escolar daqueles mestres e alunos, especialmente alguns aspectos mais inovadores e mais visivelmente inspirados em modelos sociais de matriz greco-romana. É pois do espaço social e não do espaço físico que vos irei falar.

\section{O rector}

A presidir à instituição escolar jesuítica encontrava-se um reitor, e não um principal, como acontecia noutros estabelecimentos escolares da época (em Alcalá, Salamanca, Paris ou Coimbra). Em latim clássico, o termo rector

\footnotetext{
${ }^{1}$ Ratio Studiorum da Companbia de Jesus (1599). Regime escolar e curriculum de estudos. Edição bilingue latim-português. Introdução, versão e notas por Margarida Miranda; Ratio Studiorum, um modelo pedagógico por José Manuel Martins Lopes S.J. Edições Alcalá 2008; doravante simplesmente Ratio.
} 
designava justamente 'aquele que governa'. Aplicava-se especialmente ao 'capitão de um navio', mas designava também aquele que estava à frente de um grupo de jovens, com uma função educativa. Essa é sem dúvida a explicação para a escolha deste termo na Ratio, em detrimento das outras designações correntes - além de ser também esta a designação da autoridade máxima na Universidade de Paris, modelo pedagógico da Ratio.

\section{As classes}

Também ao modo de Paris, os estudantes estavam cuidadosamente distribuídos por classes, de acordo com o seu grau de aprendizagem. A aplicação do termo classe (classis) para designar um grupo de alunos de idades próximas entre si, com o mesmo grau de instrução, a quem se oferece um tipo de programa adequado ao seu nível de aprendizagem, é evidentemente uma herança da pedagogia parisiense que passou a estruturar toda a rede escolar jesuítica - embora não tenha sido Paris a criar este sistema, mas sim os frades jeronimitas, conhecidos como Irmãos da Vida Comum.

Devemos, aliás, precisar que o termo classis não é uma invenção do século XVI, mas simplesmente a redescoberta de um termo já usado por Quintiliano, ao descrever as escolas de retórica do seu tempo (Institutiones Oratoriae, 1,2.23, por exemplo). Não significa isto porém que, até ao século XVI, não encontremos uma separação efectiva entre os cursos frequentados por gramáticos ou por teólogos. Ou que, no interior de uma disciplina, os alunos não se encontrassem mais ou menos agrupados de acordo com o programa que seguiam. Contudo, é no século XVI que a prática das classes corresponde a uma mais nítida separação sequencial de saberes, por níveis sucessivos de complexidade, gradualmente repartidos em função da idade e dos conhecimentos adquiridos. O sistema de classes era a solução para a qual o método parisiense apontava mais naturalmente. ${ }^{2} \mathrm{O}$ esforço de racionalização do ensino, a que a nova Ordem de religiosos se viu obrigada, não podia senão conduzir à adopção do mesmo sistema, devido, por um lado, à concentração crescente do ensino nos colégios e, por outro, à necessidade evidente de repartição quer dos alunos quer das tarefas, antes confiadas a um só mestre. Foi, pois, assim que teve início um aspecto que hoje nos poderia parecer tão antigo como a educação: a ordenação sequencial dos alunos e das matérias; o ensino por níveis, a construção de fundamentos sólidos antes de passar ao nível seguinte e consequentemente a existência de uma ordem numérica entre alunos e entre programas.

\footnotetext{
${ }^{2}$ Segundo Gabriel Codina-Mir (1968: 101 ss.), a mais antiga referência seiscentista ao sistema de ordenação sequencial de matérias por graus sucessivos de complexidade encontra-se no programa de Montaigu de 1509. Em meados do século XVI (1538 e 1540), ainda são numerosos os testemunhos de professores que se queixam dos mestres do seu tempo, que ensinavam os rudimentos de latim indistintamente com os oradores, os poetas, as Tusculanas de Cícero, a sintaxe dos verbos e os filósofos. Ao organizar o colégio de Nîmes (1540), Claude Baduel mostra ter consciência de instaurar um sistema novo, cuja novidade contrastava com a prática tradicional do ensino das letras.
} 
Para o estudo das letras e humanidades previa a Ratio Studiorum cinco classes: três de gramática, uma de humanidades e uma de retórica, cada uma das quais obedecia à precedência da anterior e ao cumprimento de um programa.

\section{As letras pagãs}

Antes da experiência em Paris, os mestres jesuítas tinham conhecido o colégio trilingue de Alcalá, que foi (juntamente com o colégio de Leão $\mathrm{X}$ em Roma e o colégio trilingue de Lovaina) um dos modelos inspiradores do próprio colégio Real de Francisco I de França. Os colégios dos Jesuítas tornavam-se pois colégios trilingues, para o ensino do latim, do grego e do hebraico. Com uma diferença porém: enquanto o colégio trilingue de Alcalá e os colégios trilingues protestantes nasceram e viveram em função do estudo e da interpretação da Sagrada Escritura, os colégios dos jesuítas não descuraram as letras pagãs e fizeram delas um instrumento indispensável para a eloquência sagrada - como se verifica pela preponderância da prosa e dos autores clássicos (mais do que cristãos) no programa humanístico, sobretudo na retórica.

\section{O uso do latim}

Embora trilingues, nestes colégios, a língua privilegiada era, como sabemos, o latim (Ratio,II, 8 e18). Com algumas excepções concedidas aos estudantes no dia de pausa semanal, ou nos momentos de recreio - e mesmo essas dependiam do juízo do reitor - a língua de comunicação no colégio, na sala de aula ou no refeitório, para alunos internos ou externos, era necessariamente o latim.

A recomendação era extensiva aos professores: em tudo quanto se refere às aulas não se permita nunca o uso da lingua materna. Serão desclassificados os alunos que descurarem esta norma. Por isso, o professor falará sempre em latim... (Ratio, $\mathrm{xv}, 18)$

$\mathrm{Na}$ prática, porém, sabemos que a realidade não era esta. Eram diversas as circunstâncias em que a própria Ratio recomendava ao professor o uso da língua materna, tendo em vista a compreensão dos alunos e o interesse da matéria, desde que o fizesse com dignidade e elegância, recomendava a Ratio (xviI, 5 por exemplo).

\section{As Academias}

Cientes da importância de que se revestia a formação literária, num curriculum de estudos universalmente orientado para a eloquência e a comunicação, e conscientes da inovação que aquele reforço representava no curriculum de estudos tradicional, a Ratio recomendava que, para as letras, fossem preparados professores de excelência. Cada provincial tinha a responsabilidade de assegurar uma espécie de viveiro (seges) de onde saísse uma estirpe permanente de bons professores (I, 22). Nas regras para o provincial, é evidente a preocupação pela escolha e a formação qualificada dos mestres. A inclinação para as letras e o respectivo ensino podia mesmo constituir um dos critérios para admitir os candidatos à Companhia (I, 25, 26). 
Por isso, apesar da escassez de mão-de-obra para sustentar os colégios, o professor não iniciava o seu magistério sem primeiro exercitar o ensino num lugar próprio para o efeito, o qual recebia a designação de Academia (I, 30).

Tendo surgido primeiramente em Itália e depois nas outras cidades da Europa, no Renascimento, as academias eram instituições estruturadas, com leis e estatutos próprios, destinadas ao estudo e à prática desinteressada das letras, das artes e das ciências, que tomavam o nome da primeira instituição platónica. Tal como essas primeiras academias modernas, as academias nascidas nos colégios tinham um carácter marcadamente humanístico. Reuniam os melhores alunos para o cultivo desinteressado das artes e das letras, em ambiente de lazer marcadamente humanístico, de estímulo ao pensamento, ao saber e à criação artística

Semelhantes às academias de gramáticos, de humanistas, de retóricos, de filósofos e de teólogos com que os diversos estudantes do colégio aperfeiçoavam a sua actividade artística e intelectual, as academiae ad magistros intituendos foram certamente o primeiro modelo que a idade moderna conheceu de uma escola específica para a formação professores. A herança reportava-se à escola platónica de Atenas, com que o próprio Cícero se identificava e que, através do neoplatonismo, tanto influenciara a transmissão do pensamento grego à Europa do Renascimento.

\section{As bibliotecas}

Outra marca evidente do cultivo desinteressado do saber é a importância das bibliotecas. Para satisfazer as novas exigências criadas com a descoberta da tipografia, os colégios viam-se também forçados a desenvolver novas técnicas de leitura e divulgação dos textos, a imprimir a sua própria produção para uso de alunos e professores e a organizar as suas próprias colecções de livros. Também esse era um ofício do Provincial: aplicar uma verba anual para o crescimento da biblioteca (proveniente dos bens do próprio colégio, ou de qualquer outra fonte), a fim de que todos dispusessem de uma quantidade razoável de livros - verba essa que por motivo algum seria desviada para outros fins (I, 33). Ofício do prefeito de estudos era assegurar os livros necessários para cada classe, lembrando ao reitor a necessidade de possuir livros em grande quantidade (III, 29) e, sobretudo, tomando junto dos livreiros da cidade, as precauções necessárias para a provisão regular de livros (XII, 28).

\section{As decúrias e os decuriões}

A organização e disciplina do colégio não se baseava apenas na divisão por classes. Cada classe era dividida em grupos de cerca de dez alunos - a decúria - à qual presidia o decurião (Ratio xv, 19 e 36) ${ }^{3}$. A divisão dos alunos

\footnotetext{
${ }^{3}$ A referência mais remota à prática das decúrias nos colégios da Companhia é uma carta de Cipriano Soares, de 1553, sobre o Colégio de Santo Antão: omnes in certos ordines sunt distributi,
} 
em decúrias (termo que se inspirava na divisão decimal do exército romano) era um antigo hábito monástico ${ }^{4}$ característico sobretudo dos Irmãos da Vida Comum (como, aliás, muitos outros aspectos da pedagogia destes mestres) e também conhecido do modus parisiensis. Designado por este ou por outro termo, o costume destinava-se a tornar mais consistente a organização e o governo de um grande número de estudantes, mas acima de tudo permitia fomentar o ensino mútuo entre companheiros e passar da emulação individual para uma emulação colectiva. Entre cada decúria da classe realizava-se pois uma emulação constante, por meio de competições poéticas e todo o género de disputas literárias (concertationes) que transpunham para o estudo das letras a prática escolástica da disputa e do debate permanente.

Cada decúria assumia, portanto, uma designação própria, tirada do imaginário clássico ('Romanos contra Cartagineses', por exemplo, ou então, em certos casos de imaginário mais contemporâneo, 'Turcos contra Cristãos'). Uns e outros rivalizavam não já pela espada mas pela toga, isto é, pelas litterae bumaniores.

\section{As magistraturas romanas}

Um momento alto da vida escolar de cada classe era a eleição dos cargos ou magistraturas dentro de cada decúria. Periodicamente (todos os meses ou em meses alternados), os alunos eram sujeitos a um concurso literário. Aqueles que participavam recebiam um título honorífico mais ou menos elevado consoante os méritos da sua composição.

Aqueles que escreverem melhor obterão a magistratura superior; os que se lhes seguirem receberão, por ordem decrescente, outros títulos honoríficos, cujos nomes se hão-de tirar dos cargos civis e militares gregos e romanos ...

Em regra, cada decúria tinha assim as suas próprias magistraturas e a outra os respectivos adversários, de modo que cada aluno tivesse o seu adversário correspondente. As magistraturas mais elevadas de cada uma das partes recebiam os primeiros lugares na sala de aula $(\mathrm{xv}, 35)$.

O clima de competição que se deixa adivinhar por detrás de todas estas práticas pode admirar-nos, mas se tivermos em conta a sociedade fortemente hierarquizada dos séculos XVI, XVII e XVIII, não pode deixar de nos surpreender

quos decurias, quod decem fere habeant discipulos, vocamus. Inter hos est unus qui omnium decuriarum in suo gymnasio curam habet; cuique etiam decuriae suus praeest decurio. Sic nullo labore intelligitur si quis absit, si parum in audiendo attentus, si negligens in memoria exercenda sit. Haec res maiorem nostra opinione in dies ostendit commoditatem ad multitudinem gubernandam. Sunt autem positi in decuriis pro uniuscuiusque profectu. (Litterae Quadrimestres, vol. 2, 219).

${ }^{4}$ Embora com terminologia diferente, as regras monásticas criavam as decaniae, chefiadas pelos decani, que auxiliavam o Abade no governo do mosteiro. O princípio é conhecido nas regras de S. Bento, de S. Frutuoso de Braga e de Santo Isidoro. 
que os méritos escolares acabassem por derrubar o próprio critério do nascimento social, que presidia à disposição dos alunos na sala de aula, como se vê em XII, 29.

Com este costume simultaneamente pedagógico e disciplinar, os novos questores, pretores e cônsules das cidades europeias, os novos generais, centurióes e legionários eram agora gramáticos e humanistas; pertenciam às classes dos colégios dos jesuítas e distinguiam-se não pelas vitórias políticas e militares, mas pelas vitórias poético-literárias que preenchiam o tempo de lazer na escola.

Um dos 'cargos' da classe gozava, porém, de carácter mais permanente, pois era designado pelo prefeito de estudos: em cada classe havia um censor público, que também podia ser chamado decurião máximo ou pretor ${ }^{5}$. Tal como o censor romano, o censor da classe tinha o dever de olhar pelos costumes (a cura morum), especialmente os costumes mais ligados ao estudo, e comunicar ao professor as faltas ou omissões de cada um no trabalho e na disciplina escolar. Mediante aprovação do professor, o decurião máximo tinha o direito de interceder pelos seus companheiros nas penas menores, mas essas (as penas) eram sempre aplicadas por um terceiro - o Corrector, ou Executor, já que os jesuítas estavam formalmente proibidos de castigar pessoalmente aos seus alunos. ${ }^{6}$

Sobre os castigos, aliás, a Ratio recomendava uma atitude de condescendência (Ratio XV, 40):

Não seja o professor demasiado propenso a castigar os seus alunos, nem demasiado solícito a buscar-lhes as faltas. Mais vale fechar os olhos, se o puder fazer sem prejuizo de ninguém. Não castigue ninguém fisicamente com as suas próprias mãos (pois essa é a função do executor) e abstenha-se em absoluto de lhes fazer qualquer ofensa, por palavras ou por obras. Não chame

${ }^{5} \mathrm{O}$ ofício de censor estava previsto nos estatutos da Universidade de Paris, no Ginásio de J. Sturm, de Estrasburgo, e na prática da maioria dos colégios europeus.

${ }^{6}$ Ratio, XII, 38: Para aqueles que cometerem alguma falta na aplicação ao estudo e nos bons costumes, e para quem as palavras e exortações não bastarem, o prefeito designará um executor que não pertença à Companhia. Onde não se puder ter um executor, procurar-se-á outro modo de os castigar, ou por intermédio de algum dos escolásticos ou por qualquer outro meio conveniente. Mas não se castiguem em classe as faltas cometidas em casa, a não ser por motivo grave e muito raro.

Os castigos corporais, alguns de extrema severidade, eram uma prática corrente em todas as instituições escolares, independentemente da idade do estudante. O próprio Santo Inácio de Loyola, com mais de trinta anos, escapou a uma destas punições que lhe queria administrar o Principal de Santa Bárbara, Gouveia, o velho, por achar que ele perturbava a disciplina do Colégio. Os jesuítas, porém, optaram por uma solução original (Monumenta Paedagogica, vol.1, 423424). Ao criarem, em 1551, no Colégio Romano, o cargo de executor (corrector), já ensaiado em Messina em 1549, os Jesuítas introduziram uma novidade: um leigo de fora, imparcial e neutro, de idade adulta, com estudos avançados, homem sério e piedoso que, mediante um salário honesto, executava, sem preconceitos, as sentenças ditadas aos culpados - poupando aos religiosos a imodéstia daquele acto e aos professores o odioso da função. O mesmo cargo, no entanto, já havia sido introduzido, por diferentes razões, por Jean de Standonk, em 1499, no colégio de Montaigu, célebre pela severidade da sua disciplina. 
ninguém a não ser pelo seu nome ou apelido (...).

A todos os professores a Ratio afirmava ainda algo da mais evidente modernidade: é mais fácil obter a disciplina com a esperança num honra ou numa recompensa (e com o receio da desonra) do que por meio dos castigos corporais (xv, 39).

\section{O festival literário}

Para multiplicar as recompensas não faltavam expedientes.A afixação pública das melhores poesias nos dias de festa, as declamações solenes nas ocasiões mais importantes, a atribuição dos principais papéis nas representações teatrais eram, a um só tempo, exercício literário e ocasião de verdadeiro prazer lúdico a que aspiravam as ambições de qualquer aluno. As representações dramáticas de grande aparato, que reuniam milhares de espectadores de toda a cidade, procuravam fazer de cada actor o grande orador cristão modelado por Cícero, mas também por Róscio e por Séneca.

A ocasião mais esperada em todo o ano era, contudo, a entrega pública dos prémios alcançados no festival literário, um concurso aberto a todas as classes do colégio e sujeito a um regulamento específico ${ }^{7}$. O capítulo xIV da Ratio descreve todas as normas que definiam aquelas 'Olimpíadas' literárias: as diversas provas do concurso para as diversas modalidades literárias (prosa latina e grega e poesia latina e grega); o número de prémios a atribuir; o tempo para a realização das provas; o modo de entrega das composições sob rigoroso anonimato; a composição do júri e os critérios de avaliação e, finalmente, a cerimónia pública de entrega dos prémios aos vencedores, com a maior solenidade, diante do maior número possível de pessoas, no meio de música e de novas declamações poéticas.

Como outrora com os vencedores olímpicos, a celebração dos oradores e poetas premiados, cobertos de glória, reconhecidos pelos da sua classe e pelos seus rivais, era ocasião para novas composições poéticas e musicais, por vezes encomendadas a músicos profissionais (como em Coimbra, Lisboa e Evora). O momento era de exaltação e de júbilo. Se durante todo o ano o estudante vivia quotidianamente o jogo da emulação de forma bastante cénico-dramática, naquele momento o jogo atingia o cume da escalada, e o aluno tornava-se o vencedor não da sua decúria nem da sua classe, mas de todo o colégio. Era o espírito agónico grego, não já incarnado na actividade militar - como no imaginário homérico -, não já plasmado pela competição física dos melhores dos atletas - como no tempo de Píndaro e dos Jogos Pan-helénicos -, mas pela competição poética e intelectual da vida académica - como o próprio Xenófanes teria estimado para o seu tempo.

\footnotetext{
${ }^{7}$ Além dos prémios públicos, cuja cerimónia era da responsabilidade do reitor e do prefeito, a Ratio recomendava ainda prémios privados, em cada classe, ainda que simbólicos (XII, 35 e 36).
} 


\section{O festival dramático}

Por último, se no costume dos prémios literários reconhecemos o capital simbólico das Olimpíadas helénicas, fácil é reconhecer nas tragédias e comédias do colégio, o arquétipo de um outro festival grego: o festival dramático.

Sobre este, a Ratio é muito parca em palavras (as tragédias e comédias deverão ser de tema sacro e piedoso, em latim e muito raras... Ratio, II, 13) mas a história mostrou que enquanto a Ratio se ocupava em abrandar o entusiasmo de alunos e professores por esta forma dispendiosa de representação, os colégios continuavam a distinguir-se pelos grandes espectáculos com que deslumbravam a sociedade. Unos dizian que en medio de Grecia no se pudiera representar mejor, escrevia uma testemunha ao descrever o espectáculo dado em Coimbra, em 1559.

Para uma representação em Julho, já o professor de humanidades ou de retórica teria distribuído há muito os papéis entre os alunos. Quanto aos ensaios, podiam começar em Janeiro ou Fevereiro. Envolviam toda a classe mas também músicos e cantores profissionais chamados de fora, bem como aqueles que cooperavam na construção de cenários requintados e na recolha de vestes sumptuosas e acessórios de aparato, com a colaboração entusiástica da fidalguia da cidade.

Festivais dramáticos, que envolviam todo o colégio, concursos de prosa e de poesia, o uso permanente da língua latina, a organização em classes e em decúrias, um imaginário de magistraturas romanas civis e militares, o fenómeno das bibliotecas e das academias para o estudo sistemático das letras pagãs, e a imitação explícita de Cícero, inscreviam-se num tradição escolar que nunca rompera, afinal, com a memória do triuium e do quadriuium. O capital simbólico greco-romano presidia ao programa de estudos humanísticos proposto pela Ratio e actuava vivamente nas práticas escolares quotidianas dos colégios, modelando o espaço do dever e do lazer de muitas gerações de estudantes.

\section{Bibliografia}

[Litterae Quadrimestres] Monumenta Historica Societatis Iesu, Litterae Quadrimestres. Madrid-Roma, vol. 1-7, 1894-1932.

[Monumenta Paedagogica] Monumenta Historica Societatis Iesu, Monumenta Paedagogica Societatis Iesu, vol. 1-5. Roma, 1965-1986.

Gabriel Codina-Mir (1968), Aux sources de la pédagogie des Jésuites. Le modus parisiensis. Roma, Institutum Historicum Societatis Iesu.

Ratio Studiorum da Companbia de Jesus (1599). Regime escolar e curriculum de estudos. (2008) Edição bilingue latim-português. Introdução, versão e notas por Margarida Miranda; Ratio Studiorum, um modelo pedagógico por José Manuel Martins Lopes S.J.. Edições Alcalá 2008. 